\title{
OPTIMIZATION OF SLUICE GATE UNDER FATIGUE LIFE SUBJECTED FOR FORCED VIBRATION BY FLUID FLOW
}

\author{
HANDRAL Poornakanta ${ }^{1}$, KARTIK Kadam ${ }^{1}$, DARSHAN Pawar ${ }^{1}$, KIRAN Medar ${ }^{1}$, \\ ILIYAS Makandar', ARUN Y. Patil ${ }^{2}$, BASAVARAJ B Kotturshettar ${ }^{2}$ \\ ${ }^{1}$ UG Students of School of Mechanical Engineering \\ ${ }^{2}$ Faculty of School of Mechanical Engineering, KLE Technological University earlier known as B V \\ Bhoomaraddi college of engineering, Vidya Nagar, Hubli-580031, Karnataka, \\ India.e-mail: patilarun7@gmail.com
}

\begin{abstract}
A 'Sluice' is a water-flow control gate works with sliding. So, it's a mill race, flume or a penstock, channelling water towards a water mill, traditionally a wood or metal barrier sliding in grooves that are set in the sides of the waterway. They are used in wastewater treatment of plants, and control water level and flow in watermills. However, Sluices are subjected to temperature, environment that supports corrosion, impact loading and so on. Many of those equipments operate during long time in industries and reliability is one of the most important aspects of work, there arose questions of reliability on those structural elements, because the people working nearby will be in danger due to involvement of heavy loaded parts during various possible working states. Considering these factors the gates used in industries are subjected for "Fatigue Analysis", but the normal V-channel gates which undergo corrosion, wear and continuous stress due to water flow which leads to fatigue failure, loss of material and wastage of water are still in need of this analysis. Hence there is need of an analysis to optimize the gate in terms of material, shape, and size. This paper helps to determine the fatigue strength, wear life of Sluice gate in "V-Channels". So, by using the ANSYS Workbench software, sluice gate is analysed for fatigue life under fluid flow.
\end{abstract}

KEYWORDS: Sluice gate, Fluid Force, Fatigue life, Corrosion, Optimization, Modal, water flow.

\section{INTRODUCTION}

The Sluice component is used in the systems like bridges, water canals to limit or to control the flow of the liquid. A lot of researchers worked for understanding the way that the sluices are to be placed to get a better flow and also to understand the fluid flow around the gates [1][2]. Binder [3] considered the steady flow of the water through the walls of the gate, and for different geometric conditions and established the result of how the sluice gates are to be placed in a straight and a curved path of the flow. E. B. Shuy \& H.C. Chua [4] considered the phenomenon of fluid-dynamic feed- back, which leads to organised periodic vortex shedding and oscillation of the free shear layer below a submerged sluice gate, is investigated. This paper will help us understand the fluid force impacts on the sluice gates and the shape optimization of the sluice gate.

\section{CAD AND CAE MODELING}

The overall assembly was worked in two sub assembly. Figure 1 depicts the sluice gate model sub assembly and figure 2 illustrate the sluice plate sub assembly. The detailed nomenclature of parts were highlighted in figure 3. 


\subsection{CAD Model}

This sluice component is subjected for fluid force. This fluid force has unique way of distributing the forces. This is as much as near and same as the distribution of fluid force over the length of a rectangular wall. This is given by

where

$$
F=\delta \times g \times \frac{h}{2} \times A=\delta \times g \times \frac{h^{2}}{2} \times b
$$

$\delta=$ density of fluid

$A=$ area of sluice plate $(b \times h)$

$b=$ breadth of the plate

$h=$ height of the fluid providing force
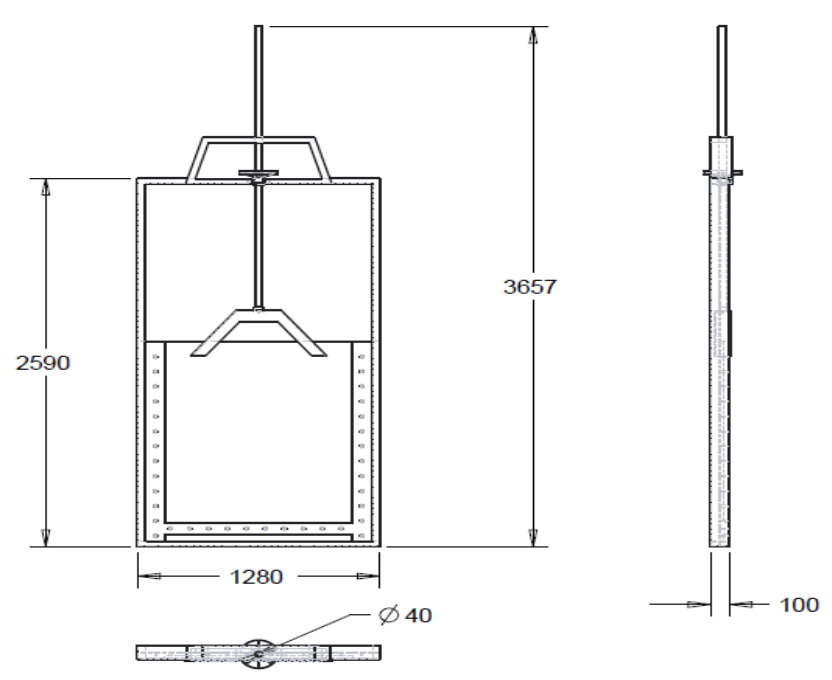

Fig 1. Model of the Sluice gate


Fig 2. Sluice plate model

From the figure 2, above without acceleration (static): $\mathrm{h}=1.402 \mathrm{~m}, \mathrm{~b}=1.270 \mathrm{~m}, \delta=1000$ $\mathrm{kg} / \mathrm{m}^{3}$ since the fluid is water. That yields a force of $1257 \mathrm{~N}$.

\subsection{Description of the system}

Sluice gate consists of following components Plate, shaft, end connecters [2][5], hand wheel, rubber strips, plate Envelope and nut-Bolt assembly. These are all made up of Structural steel. Total Weight: $504.53 \mathrm{~kg}$. 




Fig 3. Nomenclature of sluice gate.

\subsection{Material properties}

The entire assembly model was assigned with structural steel as a material shown in table 1 .

Table 1. Material properties of Sluice gate (structural steel)

\begin{tabular}{lll}
\hline Property & unit & value \\
\hline Density & $\left(\mathrm{kg} / \mathrm{m}^{3}\right)$ & 7800 \\
Poisson's ratio, v & & 0.3 \\
Co-efficient of Thermal expansion & & $2.1 \mathrm{e}^{-5}$ \\
Elastic modulus, E & $(\mathrm{GPa})$ & 210 \\
Yield strength & $(\mathrm{MPa})$ & 250 \\
Ultimate strength & $(\mathrm{MPa})$ & 460 \\
\hline
\end{tabular}

\subsection{Reason for failure}

Failure of the component is mainly due to two reasons

1. Non uniform flow of the fluid.

2. Corrosion effect.

The prediction of failure can be carried out using optical method [6]

\section{FINITE ELEMENT ANALYSIS}

Finite Element Analysis is the best method to analyze the problem with virtual way. It caters to all the prerequisites of industry ready product with nearest optimal solution with respect to optimization.

\subsection{Static Structural Analysis}

Every problem whenever allowed to be solved for finite element analysis, first step it would be subjected to is a case of static structural analysis. Further, the work will be subjected to various other types of analysis.

Meshing: Every meshing process starts with generic auto mesh and then it will subjected to refinement of model with lower range of element size. An element type of Tetrahedron with second order and element size of $20 \mathrm{~mm}$ was considered[7]. From figure 4 it can be inferred that mesh with uniformity by patch confirming method using ANSYS Workbench. 
Loading Conditions: The plate is subjected for the direct load, since for a particular flow height the components are configured independently. From figure 5, fixity on either side of sluice gate was scoped and a force of $31402 \mathrm{~N}$ was applied on the area after converting hydrostatic pressure to a force based loading.

Contacts: Bonded contacts.

Boundary Conditions: The gate is supported by sides, which makes the sides of end envelope as fixed. Due to the limitations of the software, the threaded components are considered and modelled flat (without thread) and analyzed.

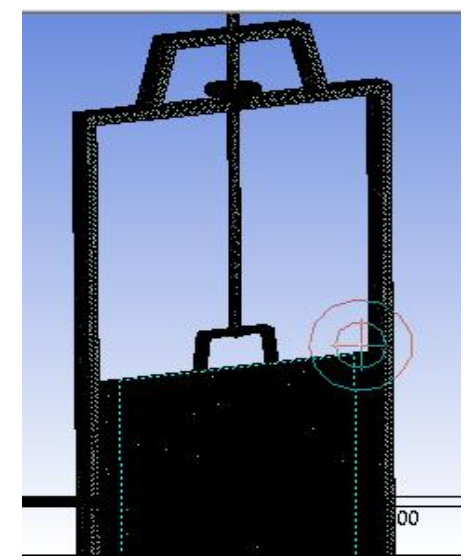

Fig 4. Meshing of the Sluice Gate

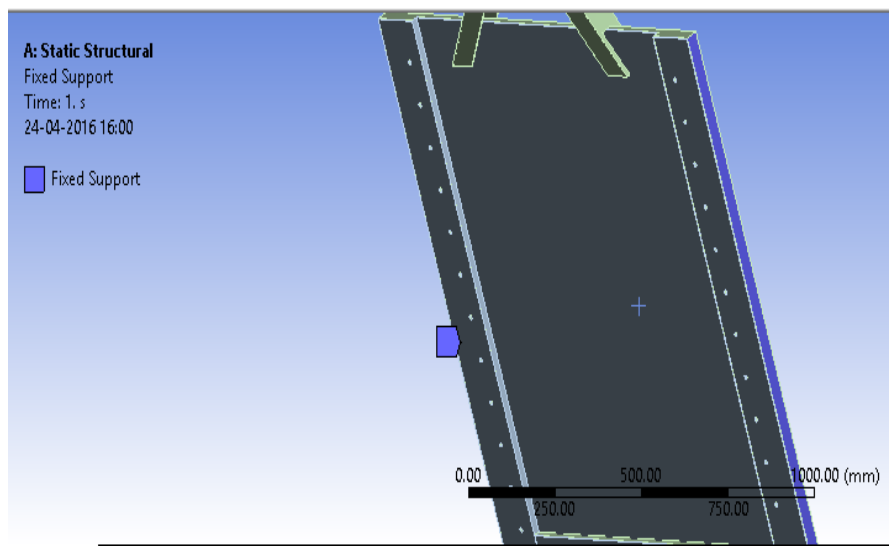

Fig 5. Boundary Conditions on the plate.

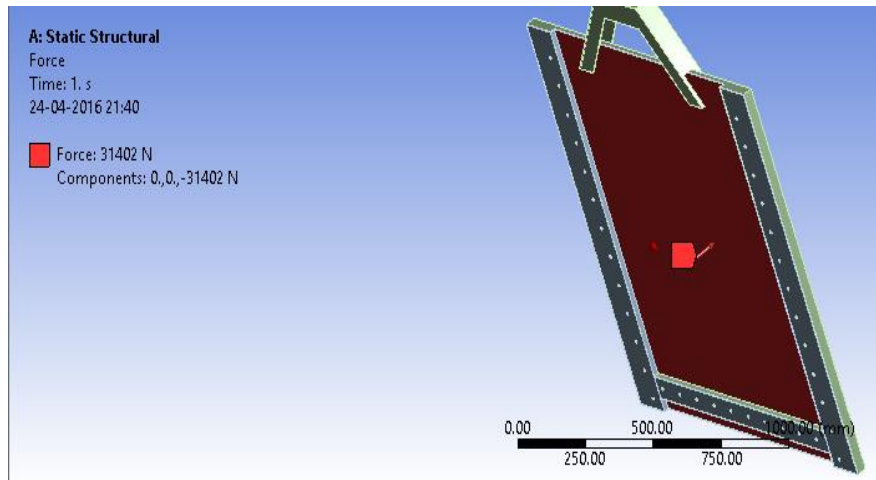

Fig 6. Loading Conditions.

From figure 8 and 9 , the deflection and stress are minimal at the considered theoretical force and under static condition, but even though one thing that is particularly clear is that the 
component experiencing much of the deformation and the stress is the plate. The factors to be held accountable are corrosion and the vibrations.

\subsection{Corrosion Analysis}

Since there is contact of the Sluice plate with the water, there will be corrosion the plate and its effect is understood by the analysis done on it by using below assumptions and properties.

\subsubsection{Assumptions}

The corrosion factors are time varying, environmental varying, and even it varies with the composition of the material. So, but any moment the design considerations are made for the worst case, thus a corroded material with $2 \mathrm{~mm}$ thickness and the properties which are assumed to be about $1 / 4^{\text {th }}$ of the material selected. The corroded material is found to be [8]

$$
\mathrm{Fe}^{2+}+2 e^{-} \rightarrow \mathrm{Fe}
$$

and the mechanical properties of the corroded material are as follows

\subsubsection{Corroded steel Material properties}

As the condition suggests that a corroded steel will fail early in comparison to non corroded steel. The details of material properties for corroded steel are disclosed in table 2 .

\begin{tabular}{lcl}
\multicolumn{3}{l}{ Table 2. Material properties of Sluice gate (Corroded steel) } \\
\hline Property & unit & value \\
\hline Poisson's ratio, $v$ & & 0.3 \\
Co-efficient of Thermal expansion & & $4.2 \mathrm{e}^{-5}$ \\
Elastic modulus, E & $(\mathrm{GPa})$ & 105 \\
Yield strength & $(\mathrm{MPa})$ & 55 \\
Ultimate strength & $(\mathrm{MPa})$ & 110 \\
\hline
\end{tabular}

To make the analysis easier and more promise able with the results the alternating and mean stress cycles are kept similar to that of the structural steel cycles. And as the only part of the system found with severe deformation is plate, analysis is carried out on plate henceforth.

\subsection{Non linear Analysis on the Sluice Plate}

Non-Linear, Fatigue analysis with forced vibration on the corroded plate.

Boundary Conditions: The plate is fixed by the two vertical sides and by the top end connector, this connecter is provided with cylindrical support, fixed tangentially and has degree of freedom in radial and axial direction by referring to figure 5 and 6.

Loading Conditions: Fluid-force (Dynamic).

$$
F=\delta \times g \times \frac{h^{2}}{2} \times b=1000 \times 9.81 \times \frac{1.42^{2}}{2} \times 1.27=12560.86 \mathrm{~N}
$$

Is ratio type load as per ANSYS Workbench.

The loading is not fully reversed. The force has to be positively reversed. Thus the fluid force is considered for a height of $75 \%$ of the plat height. That will give us the dimensions $\mathrm{h}=1.065 \mathrm{~m}$ and $\mathrm{b}=1.27 \mathrm{~m}$ and the fluid force is $\mathrm{F}=7065.4845 \mathrm{~N}$. With a load multiplication factor of $2.5, \mathrm{~F}=17663.71 \mathrm{~N}$. The load is further fluctuated for the next $25 \%$ by means of taking the load fluctuation ratio as 1.25 .

From the figure 7 we can see the two different layers. The grey coloured layer is the corroded steel layer and the other is normal structural steel solid part. 
Given the specification of the components, excluding the nut-bolt assemblies, the results are found as follows Plate weight $=344.14 \mathrm{~kg}$. From figure 10 and 11 it can be analysed that a von mises stress of $25.25 \mathrm{MPa}$ and a total deformation of $0.2846 \mathrm{~mm}$ was recorded respectively for the earlier set condition.

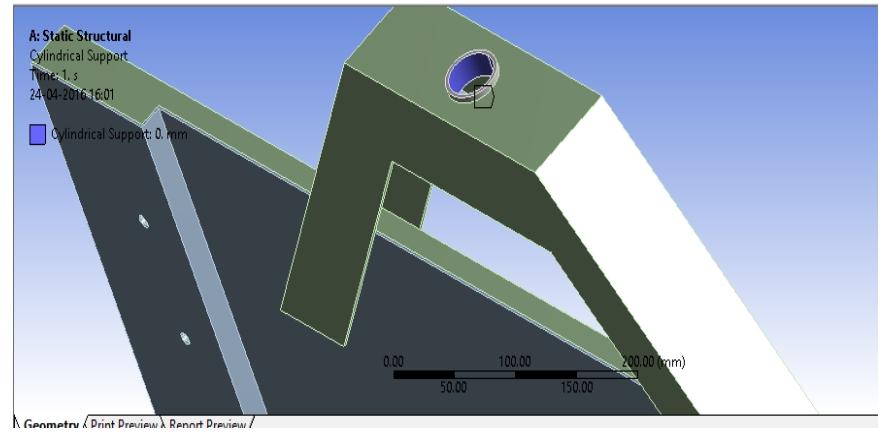

Fig 7. Corroded layer put on the plate.

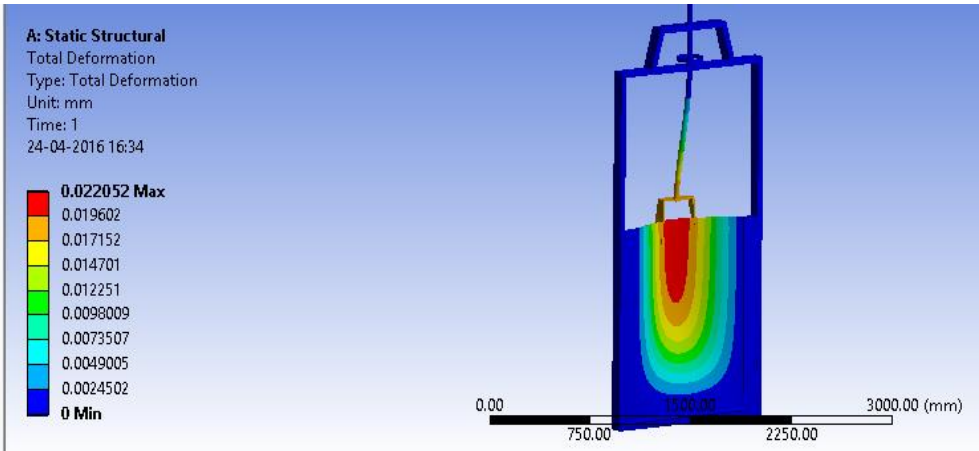

Fig 8. Deformation in the Sluice Gate

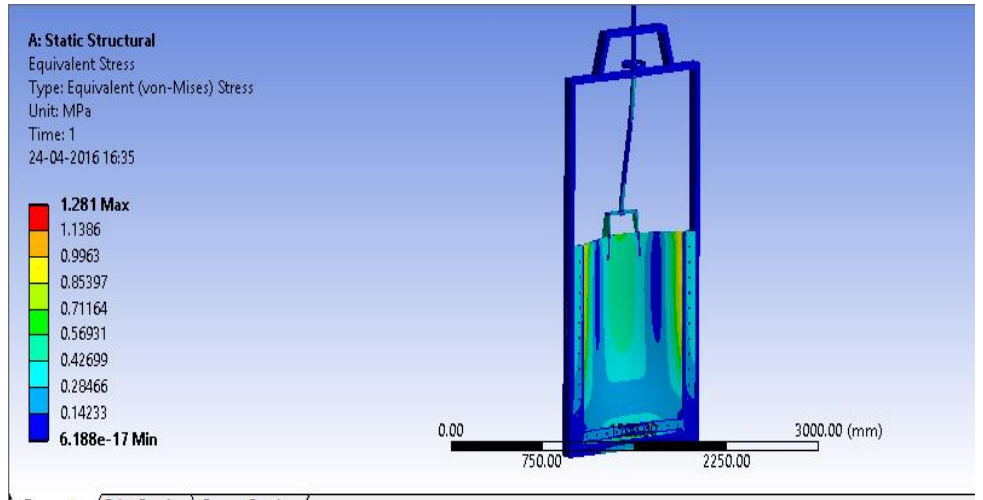

Fig 9. Stress Concentration in the Sluice gate

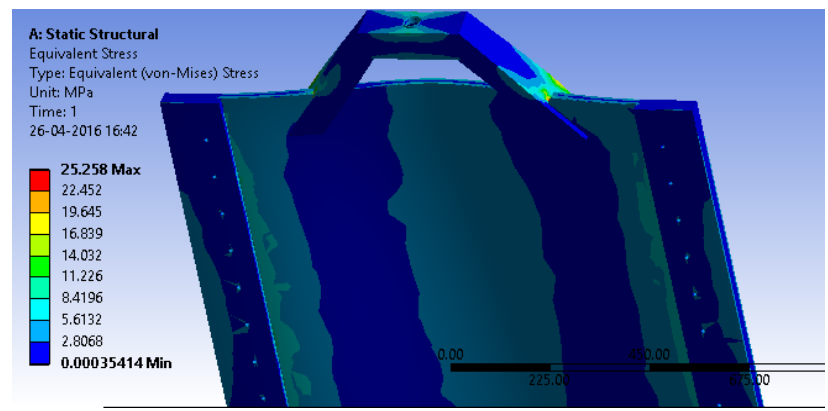

Fig 10. Von mises Stress is $25.258 \mathrm{MPa}$ 


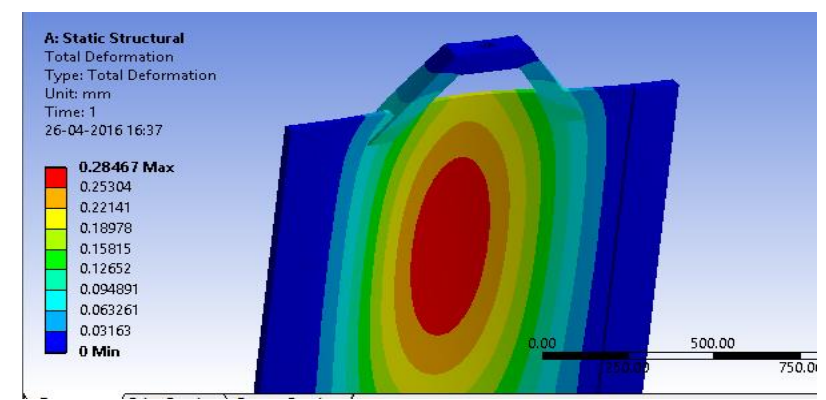

Fig 11. Total Deformation is $0.28467 \mathrm{~mm}$

\subsection{Fatigue Analysis}

Fatigue is phenomenon which occurs when there is load acting on something continuously, in which stress developed will increase to failure very quickly. There are different measures in the fatigue, they are life of the component, damage on the component, safety factor to be applied on it and bi-axiality indication[9][10]. From figure 12, it is quite clear that life of the plate is showing a design life with minimum cycle life $=2.5 \mathrm{e}^{5}$ cycles.

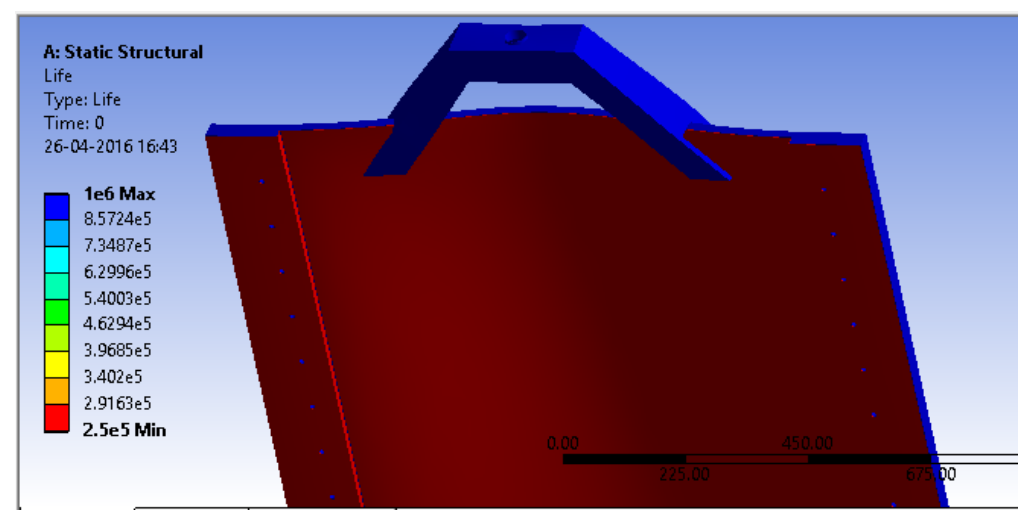

Fig 12. Life of the plate

The component is then subjected for modal analysis for a check of forced vibration. From figure 13(a-b) it can be understood that bending is the predominant factor and figure 13(c-d) illustrates bending and twisting behaviour with respective mode shapes and figure 13(e-f) deals with pure twisting behaviour.

Table 3. Showing Frequencies of different modes

\begin{tabular}{ccc}
\hline Modes & $\begin{array}{c}\text { Frequency } \\
(\mathrm{Hz})\end{array}$ & $\begin{array}{c}\text { Deformation } \\
(\mathrm{mm})\end{array}$ \\
\hline 1 & 105.14 & 4.1501 \\
2 & 128.47 & 4.5121 \\
3 & 170.52 & 5.8376 \\
4 & 255.95 & 10.403 \\
5 & 265.12 & 16.083 \\
6 & 300.27 & 27.261 \\
\hline
\end{tabular}

From the Table 3, we can confirm that the increase in frequency increases the deformation of the component as well. Looking at the stress developed, a higher factor of safety must have been considered for the design. It is redundant in the design. So, there is a need of optimization of the material, the most.

\section{OPTIMIZATION}

Optimization is a buzz word currently in CAE industry and it does save lot of amount in terms of material, design and quality aspect. 




Fig 13. Deflections under vibration a.) Mode 1 b.) Mode 2 c.) Mode 3

d.) Mode 4 e.) Mode 5 f.) Mode 6

\subsection{Concept Design 1}

From figure 14, the existing model went through with exhaustive analysis and allowed for $10 \mathrm{~mm}$ thickness of material removal from the back portion of the plate, and the guide strip is made hollow with edges having a thickness of $4 \mathrm{~mm}$. Further slots of $40 \mathrm{~mm}$ wide and $4 \mathrm{~mm}$ thick are removed in numbers of 14.

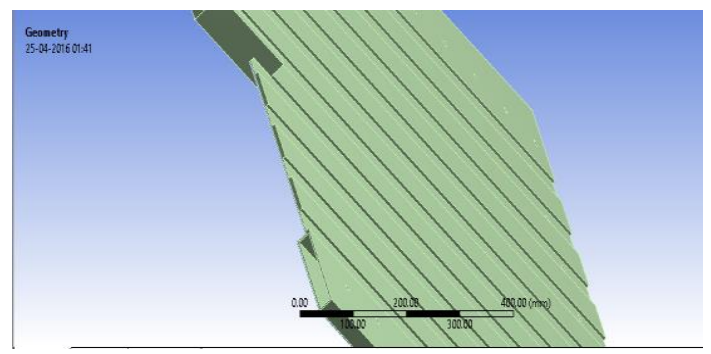

Fig 14. $1^{\text {st }}$ Optimized Part of the Plate

This variation has brought the weight from $344.14 \mathrm{~kg}$ to $104.28 \mathrm{~kg}$. Now for the same boundary condition validation of the design carried out in terms of modal analysis for the non linear component. The results from figure 15 illustrate $217.5 \mathrm{MPa}$ for Von-mises stress and total deformation was shown in figure 16 with $10 \mathrm{~mm}$. 


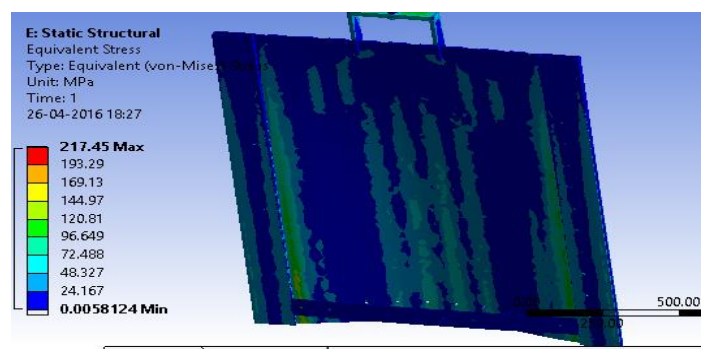

Fig 15. Static Stress of the $1^{\text {st }}$ Optimized plate Induced stress is $217.45 \mathrm{MPa}$

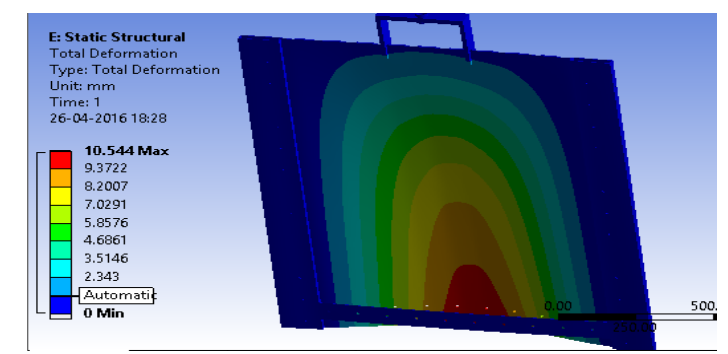

Fig 16. Static Deformation of the $1^{\text {st }}$ Optimized plate

From figure 17, it can be observed that even though the design is safe as per the stress concentration, but the damage level is very high. That is the rate of damage is 55590 .

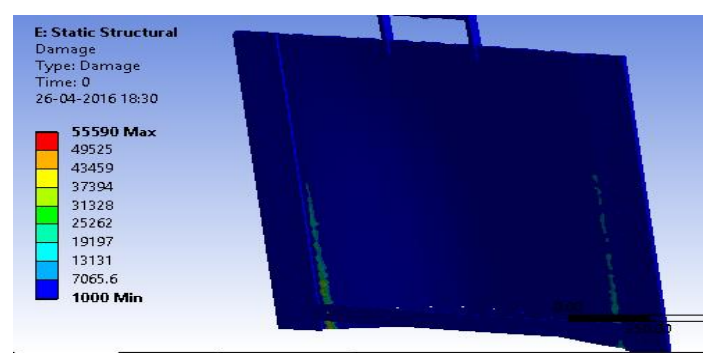

Fig 17. Damage on the $1^{\text {st }}$ Optimized plate

Also the life cycle is real less. The minimum life cycle is 17989 cycles as given in the below figure 18.



Fig 18. Life of the $1^{\text {st }}$ Optimized plate

So this optimization is not suitable. But, the point is to be noted that the deflection is more at the centre of the plate. So, material addition is necessary at the centre of the plate. With these necessary adaptations in the design, another optimization is found as given further.

\subsection{Concept Design 2}

From figure 19 it is observed that criss-cross structure was developed to reduce the weight as well as maintain the structural rigidity of the member. Figure 20 depicts the details of back side of the sluice gate. 


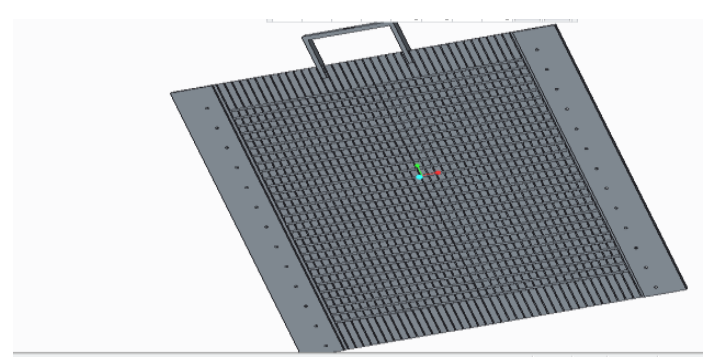

Fig 19. $2^{\text {nd }}$ Optimized plate

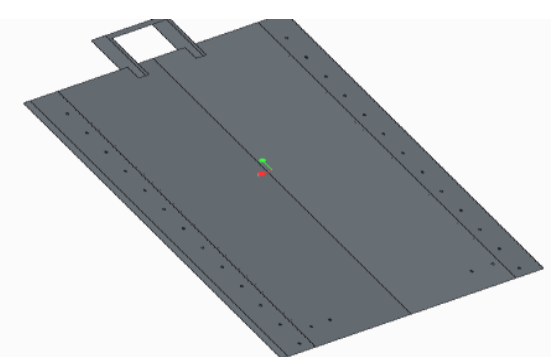

Fig 20. $2^{\text {nd }}$ Optimized plate

$10 \mathrm{~mm}$ of material is removed from the back portion of the gate. A hollow section is made along the guide strips with the wall thickness of $3 \mathrm{~mm}$. Small strips are of $5 \mathrm{~mm}$ wide are made at the front of the plate (the surface facing the fluid flow) both in horizontal and vertical direction of the plate along the length of the component.

This type of material cut will provide the fluid force a higher area of contact, and as per the fluid force equation, the amount of force that a material with some definite area can bear a particular force, since the contact area is increased for the same force, the effect of loading is reduced a bit. Also, as confirmed from the first optimization, material is added at the centre of the plate, in a doomed shape, or we can say a ' $\mathrm{V}$ '-shape from the top view of the component.

This V-shape optimization will help the system to distribute the load towards the supports the most. And force on a support has a least effect of deformation and less stress on the plate component. Design weight was be brought to $114.28 \mathrm{~kg}$. With all these data, further analysis resulted in von Mises stress of $82.94 \mathrm{MPa}$ and total deformation of $1.89 \mathrm{~mm}$ depicted in figure 22.

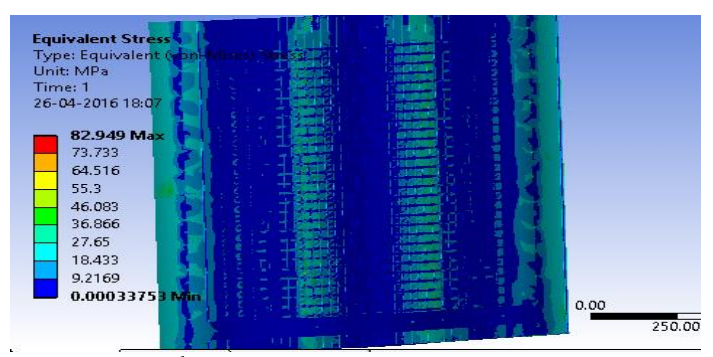

Fig 21. Static Stress of the $2^{\text {nd }}$ Optimized plate Von Mises Stress is $82.949 \mathrm{MPa}$

This is $33.179 \%$ of the yield strength of the material used for the gate. So, it is safe with a factor of safety of 3.013 .

Further, the deformation is reduced in large amount, compared to the first optimization. That is about $81.99 \%$ of reduction. So, the optimization is good for no linear condition, and still it need conformation for vibration analysis. The under forced vibration, the following results were worked out with figure 23 (a-c) illustrating mode 1 to mode 3 with bending and twisting mode shapes observed in the sluice gate. 


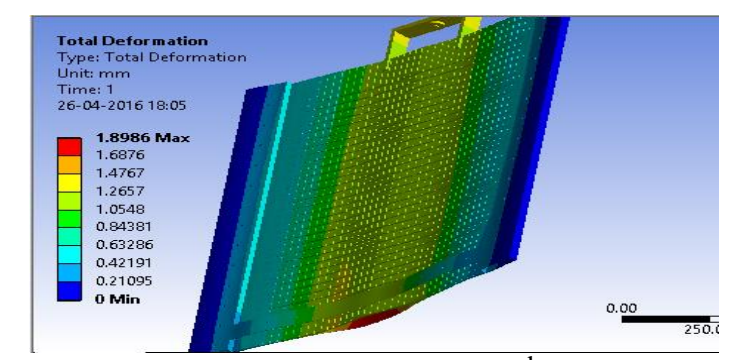

Fig 22. Static Deformation of the $2^{\text {nd }}$ Optimized plate

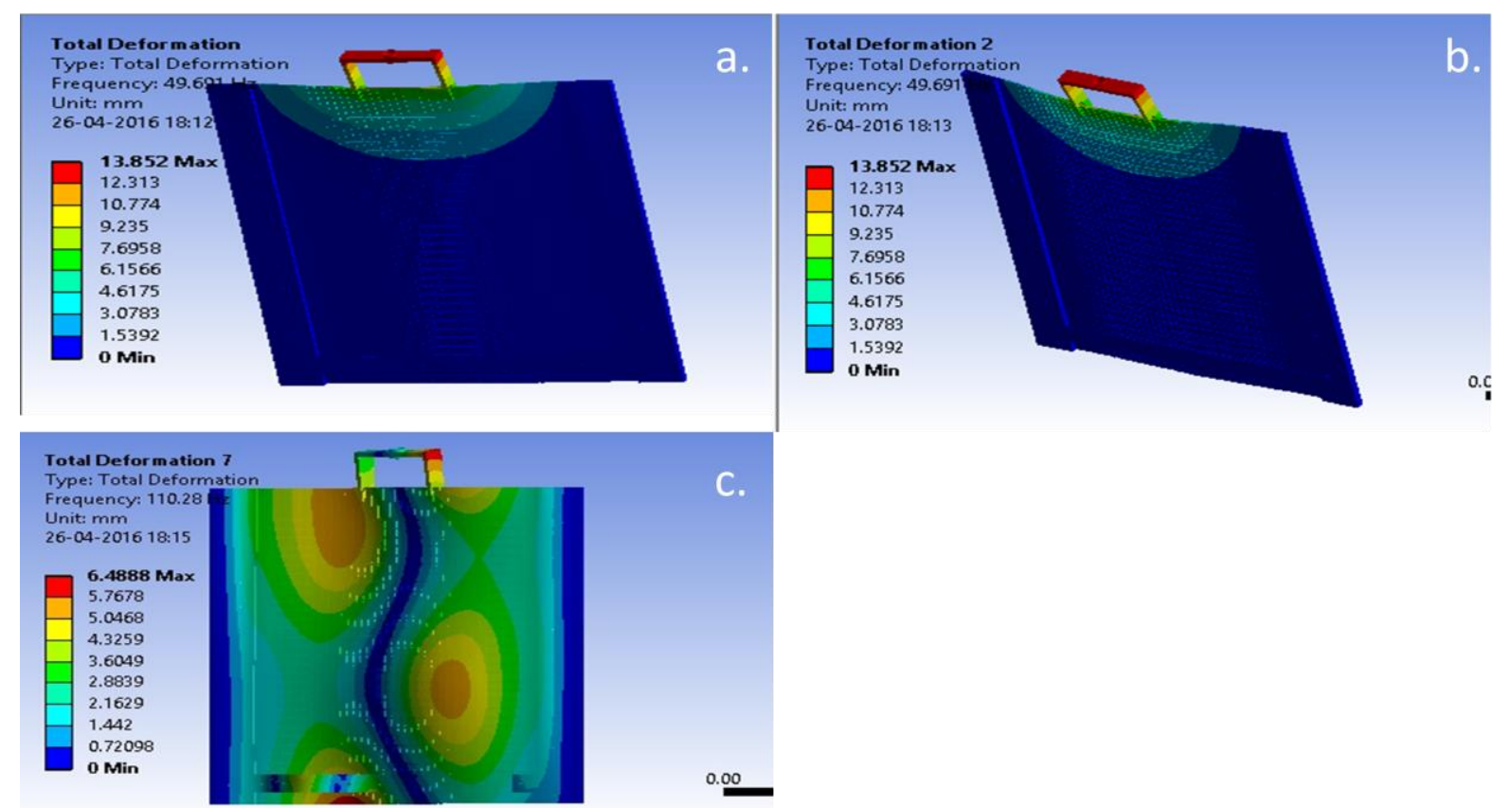

Fig 23. Deflections under vibration a.) Mode 1 b.) Mode 2 c.) Mode 3

Table 4. Frequencies of various modes of the $2^{\text {nd }}$ Optimized plate

\begin{tabular}{cll}
\hline Modes & $\begin{array}{l}\text { Frequency } \\
\text { (Hz) }\end{array}$ & $\begin{array}{l}\text { Deformation } \\
(\mathbf{m m})\end{array}$ \\
\hline 1 & 49.691 & 13.852 \\
2 & 49.691 & 13.852 \\
3 & 110.28 & 6.488 \\
\hline
\end{tabular}

From Table 3 and Table 4, we can consider there is a drastic reduction in deformation value from $27 \mathrm{~mm}$ to $6.4 \mathrm{~mm}$. In case of concept design 1 frequency was in the range of 100 to $300 \mathrm{~Hz}$ with deformation varying at 4 to $27 \mathrm{~mm}$ were as in concept design 2 frequency is gaining higher value with reduction in its deformation value. Which is a good sign for structural rigidity of the system. The other reason to consider design 2 is optimal design with factor of safety slightly ahead of 3 . The deformation values are true to real time conditions, these deflections are at acceptable ranges for a bulk matter as such.

The fatigue life analysis results for the same are given next. 


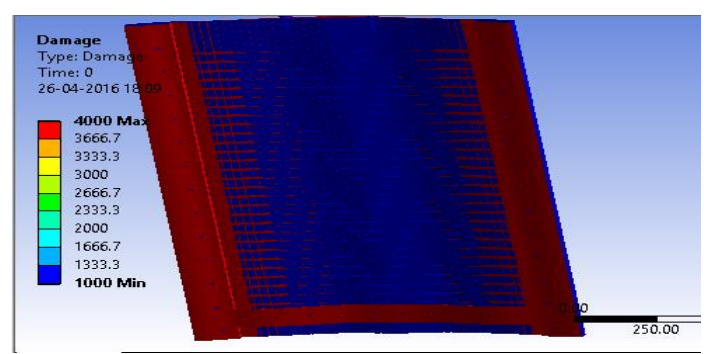

Fig 24. Damage on $2^{\text {nd }}$ Optimized plate

From figure 24 it can be observed that as expected the damage is mainly for the corroded layer and the mostly near the outer surfaces.

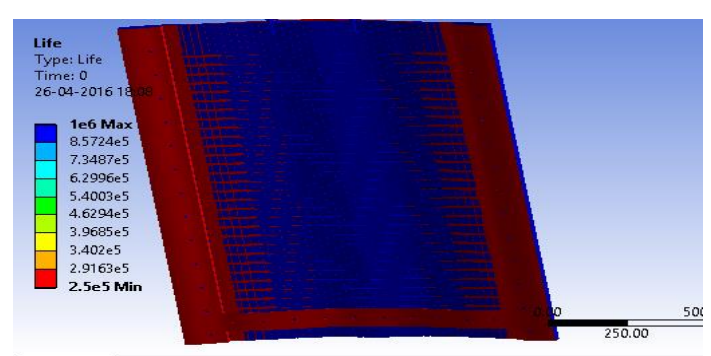

Fig 25. Life of $2^{\text {nd }}$ Optimized plate

From figure 25 it can be concluded that life of optimized plate restricted to minimum life cycle of $2.5 \mathrm{e} 5$ higher than the previous record. So, a correction for the corrosion is all needed.

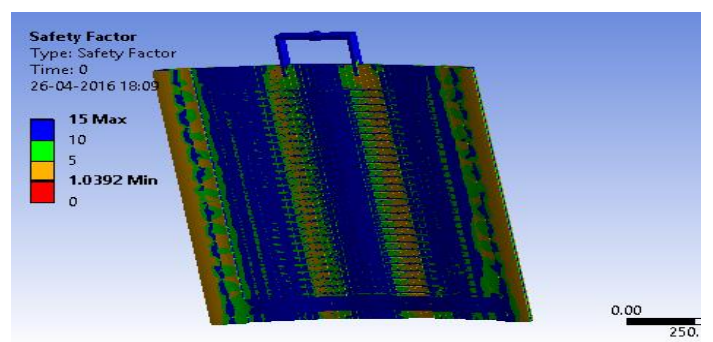

Fig 26. Safety Factor of $2^{\text {nd }}$ Optimized plate

From figure 26, Factor of safety got reduced to 1.0392 which is approximately compatible for general standard sluice gate conditions. It is recommended that at least two to three iterations have to be conducted in order to arrive at convergence of solution [11]. Now, even the safety factor is reduced for the corrosion layer, and the rest is same old. The plate will survive for a sufficient life period, if the corrosion effect is nullified. So, provision of a corrosion inhibitor layer might increase the cycle life. Other than that, the design is optimal for fatigue life and modal analysis.

\subsection{Comparative study}

Based on the two concept design with their importance in terms of design, structure comparison can be illustrate as follows in table 5 .

Table 5. Comparative study for concept models

\begin{tabular}{|l|l|l|l|l|l|l|l|}
\hline $\begin{array}{l}\text { Sl. } \\
\text { No }\end{array}$ & $\begin{array}{l}\text { Concept } \\
\text { model }\end{array}$ & $\begin{array}{l}\text { Thickness } \\
\text { reduction } \\
(\mathbf{m m})\end{array}$ & $\begin{array}{l}\text { Design } \\
\text { Structure }\end{array}$ & $\begin{array}{l}\text { Factor } \\
\text { of } \\
\text { Safety }\end{array}$ & $\begin{array}{l}\text { Von Mises } \\
\text { Stress } \\
\text { (MPa) }\end{array}$ & $\begin{array}{l}\text { Total } \\
\text { Deformation }\end{array}$ & Weight \\
\hline 1 & Concept 1 & 10 & Straight & 1.89 & 217 & 10.54 & 104 \\
\hline 2 & Concept 2 & 10 & Criss-cross & 1.04 & 82.94 & 1.89 & 114 \\
\hline
\end{tabular}




\section{RESULTS AND DISCUSSION}

Further improvements like addition of corrosion inhibitor layer would definitely reduce the damage. The concept design 2 slightly edge over concept design 1 in case of deformation and factor of safety was also achieved at mediocre level. Weight optimization was another aspect, we did found that reduction in weight of only the plate from $344.14 \mathrm{~kg}$ to about $114 \mathrm{~kg}$ with some more improvisation necessary to be made as standard test case. The proof of concept testing is essential before we consider the final design.

\section{CONCLUSION}

Analysis on the sluice component has proven that there are still possibilities of improvement on the gate. And these improvements may help in the reduction of material as per the results obtained. The analysis carried on are namely- Static structural, Fatigue, Modal and Optimization has been done on the sluice gate and it has been found that it is safe for all the analysis.

\section{ACKNOWLEDGEMENT}

The support extended by the BVB College of Engineering and Technology authorities and the CAE team is highly appreciated and acknowledged with due respect. The authors team grateful to management Dr. P G Tewari and our beloved Vice Chancellor Dr. Ashok S Shettar for their continuous support in completing the task.

\section{REFERENCES}

[1] F. M. White. Fluid Mechanics, Mc Graw-Hill 1999.

[2] ASTM E 837-13a Standard Test Method for Determining Residual Stresses by the Hole Drilling Strain-Gage Method, New York, 2001.

[3] B. J. Binder. A Non-Linear Dynamical System: Flow Past a Sluice Gate. Australasian Journal of Engineering Education 2009 (15), No. 2, 27 - 34. DOI: 10.1080/22054952 .2009.11464022

[4] E. B. Shuy, H. C. Chua. Fluid-dynamic feed-back in shear layer oscillation below a submerged sluice gate. Journal of Hydraulic Research 1999 (37), No. 1, 107 - 120, DOI:10.1080/00221689909498535.

[5] D. V. S. Verma M.ISH, Arun Goel M.ISH. Scour downstream of a sluice gate. ISH Journal of Hydraulic Engineering 2005 (11), No. 3, 57 - 65. DOI: 10.1080/09715010. 2005.10514801.

[6] M. Pástor, P. Frankovský, M. Hagara, P. Lengvarský. The Use of Optical Methods in the Analysis of the Areas with Stress Concentration. Journal of Mechanical Engineering - Strojnícky časopis 2018 (68), No. 2, 61 - 76. DOI: 10.2478/scjme-20180018 .

[7] Arun Y Patil, Shreyas Kulkarni, Shreesha Koppal, Shridhar N Mathad. Design and Analysis of Backpack Structure for School Children using FEA Tool. Int. J. Adv. Sci. Eng. 2018 (5), No. 1, 862 - 870. DOI: 10.29294/IJASE.5.1.2018.862-870

[8] Oscar Castro-Orgaz, Willi H. Hager. Transitional flow at standard sluice gate. Journal of Hydraulic Research 2014 (52), No. 2, 264 - 273, DOI: 10.1080/00221686. 2013.855951 
[9] R. Owsińskir, A. Niesłony. Identification of Fatigue Cracks on the Basis of Measurable Changes in System Dynamics. Journal of Mechanical Engineering - Strojnicky časopis 2017 (67), No. 2, 77 - 84, DOI: 10.1515/scjme-2017-0020

[10] M. L. Shreeshail, Arun Y. Patil. Effective use of unused heat energy from burnt fuel source. International Journal of Applied Engineering Research 2015 (10), No. 48, 639 -641 .

[11] Arun Y. Patil, N. H. Umbrajkar, G. D. Basavaraj, R. C. Gireesha, K. G. Kodancha. Influence of Bio-degradable Natural Fiber Embedded in Polymer Matrix. IMME17, Material Proceedings, Elsevier, 5(2), 7532 - 7540, 2018. 